\title{
¿Qué es una jirafa? \\ Educación, investigación, cuidado de los animales y entretenimiento en los zoológicos
}

Francisco J. Serrano

Universidad Autónoma de Zacatecas

fserrano@uaz.edu.mx

\section{¿Por qué tenemos zoológicos hoy en día?}

¿Para qué queremos hoy en día zoológicos? Los zoológicos podrían ser instituciones vestigiales de épocas en las que poseer una gran colección de animales era consonante con el poder político y económico de su dueño. Dale Jamieson nos recuerda que los romanos tenían grandes colecciones de animales que serían sacrificados durante los juegos. El emperador Trajano, por ejemplo, sacrificó once mil animales durante 123 días consecutivos para celebrar la conquista de Dacia (entre los que había leones, tigres, elefantes, rinocerontes, jirafas, búfalos, ciervos, cocodrilos y serpientes); ésta era una práctica común en todo el Imperio romano y cada ciudad y arena poseía su reserva de animales para ser sacrificados (Jamieson, 2006: 132). Durante siglos, reyes y hombres poderosos albergaron y sacrificaron animales para demostrar su 
poder. Estas prácticas, me parece, están muy alejadas de la sensibilidad que prevalece hoy en día por los animales y de si los zoológicos son una mera continuación de las instituciones vestigiales.

Sin embargo, hay que reconocer que, incluso, en el mundo antiguo existía cierto interés científico por los animales. Aristóteles estudiaba animales que le enviaba Alejandro Magno desde sus conquistas. El emperador Ptolomeo II construyó el zoológico de Alejandría para satisfacer su curiosidad científica. Este interés revivió en la época moderna. Por ejemplo, el Muséum national d'Historie naturelle se fundó en París en 1793 con el propósito fundamental de hacer investigación zoológica; pocos años después, en 1817, Stamford Raffles estableció «la necesidad de una colección de animales para intereses científicos y para el interés general», lo cual condujo a la creación de la Zoological Society of London (Hutchins y otros, 1996: 253). En consonancia con estas ideas, en el siglo XVIII surgieron los primeros zoológicos modernos en Viena, Madrid y París (Jamieson, 2006:132). Pronto otros zoológicos les siguieron por todo el mundo (en México, el zoológico de Chapultepec fue inaugurado en 1923).

Cultivar el interés científico por los animales no es el único propósito de los zoológicos. Hoy en día se acepta que las tareas distintivas de los zoológicos sean la educación del público, la investigación científica, el entretenimiento y el cuidado de los animales. Los zoológicos pretenden contribuir a la educación del público sobre diferentes aspectos de la conducta y la vida de los animales; realizar investigación sobre las condiciones de vida de las diferentes especies, su salud, su conducta y su conservación (en condiciones en las que la mayoría de los ecosistemas del planeta están comprometidos por las economías humanas); contribuir al entretenimiento 
de las personas motivando a que salgan de sus casas, se reúnan y tengan actividades familiares, educativas, sociales, etc. Finalmente, pretenden cuidar la salud física y anímica de los animales a su cargo. A continuación, examinaré brevemente las condiciones en que se desarrollan estas tareas.

\section{De las rejas hacia dentro}

Al considerar lo que sucede en los zoológicos, de las rejas hacia adentro, parece claramente dudoso que éstos cumplan satisfactoriamente con sus tareas distintivas, excepto, quizá, la de servir como entretenimiento del público. Si ésta es su única actividad realizada con algún éxito, ¿qué distinguiría a los zoológicos de los ya casi extintos circos o, en virtud del cruel y gratuito sufrimiento que infringen a los animales a su cargo, del toreo o el jaripeo? Si estas consideraciones son plausibles, entonces sostendré que es dudoso que los zoológicos tengan razón de ser hoy en día.

Dale Jamieson (2006) ha probado persuasivamente que los zoológicos fallan sistemáticamente en cumplir las tareas mencionadas. En relación con la educación, cita evidencia sobre el poco interés general que tienen los zoológicos. Desde el punto de vista de los especialistas en zoología, estos centros fallan rotundamente en ofrecer educación importante sobre los animales. Ellos observan que la gente pasa rápidamente de una jaula a otra y suelen atender sobre todo a las crías, a los animales que se alimentan o los que hacen algún ruido. Es dudoso, en efecto, que en las condiciones de los zoológicos la gente pueda aprender algo importante sobre la fisiología, la conducta o la sobrevivencia de los animales porque, para empezar, están en cautiverio y en tales condiciones no 
puede haber observación interesante sobre la conducta típica o aquello que necesitarían para sobrevivir como individuos y como especie. (Respecto de la fisiología, y a propósito del caso de la jirafa del zoológico de Copenhague, Mario, en la siguiente sección diré más sobre por qué los zoológicos se resisten a ofrecer buenas lecciones en este sentido). El interés actual por el tema puede ser cultivado mediante documentales, películas, libros especializados, etc. Los zoológicos, como instituciones educativas, parecen irrelevantes.

De manera implícita, los zoológicos enseñan que los humanos pueden disponer de los animales, aun bajo las supuestas mejores intenciones; los humanos tienen derecho a decidir el futuro de los animales, a cuidarlos, a conservarlos, a estudiarlos, a administrarlos, a exhibirlos, etc. Si la educación fuera el único interés que tenemos en los zoológicos, debería responder a estas observaciones.

Jamieson continúa señalando que realmente muy pocos zoológicos realizan investigación científica. Los escasos investigadores de tiempo completo asociados con los zoológicos prefieren, ellos mismos, realizar su trabajo con animales en libertad. De modo que a los zoológicos sólo les queda la investigación sobre la conducta, la anatomía y la patología de los animales. Respecto al primer tema, no parece que los zoológicos puedan decir algo interesante. La conducta de los animales en cautiverio no es su conducta natural. Estudiar la conducta en cautiverio se refiere a esas actividades neuróticas que revelan las malas condiciones en que viven en el zoológico o aspectos que no parecen interesantes. Los zoológicos pueden estudiar esas conductas neuróticas para encontrar modos de evitarlas, usualmente mejorando las condiciones en que viven los animales. Lo anterior sólo es pertinente si aceptamos la existencia de los zoológicos. Por otra parte, 
en libertad, los animales enfrentan problemas diversos que muestran los aspectos más fascinantes de su conducta, como escapar de predadores, cazar, enfrentar escasez de alimentos, encuentros con otros animales, etc.; es evidente que nada de esto hay en los zoológicos o al menos no existe de una manera realmente instructiva. Los estudios sobre anatomía y patología parecen más interesantes porque permiten a los zoológicos tener animales sanos y longevos. De nuevo, como también observa Jamieson, esto sólo parece interesante si aceptamos la existencia de los zoológicos (Jamieson, 2006: 137). Si no existen buenas razones para tenerlos, estos temas pierden toda su importancia.

La última tarea que nos resta considerar, que es la contribución de los zoológicos a la conservación y el cuidado de los animales, no encuentra tampoco buenas razones. Reitero que muy pocos zoológicos hacen investigación sobre la conservación de los animales. Aun así, muchos tienen familias o individuos de animales en severo peligro de extinción o ya extintos en su medio ambiente. ¿Qué tan significativos son estos casos? Jamieson indica que la falta de diversidad genética de los animales en cautiverio impide que sean viables, tanto para los programas de reproducción de los propios zoológicos como para los de reintroducción al hábitat de la especie (cuando ésta es aún viable). Pese a los intercambios de individuos entre zoológicos, éste es un fuerte problema y restringe la viabilidad de las familias de animales (diré más sobre este tema en la siguiente subsección). Por otra parte, después de algunos años en cautiverio, tanto la conducta como la genética de los animales tienden a alejarse de sus contrapartes en libertad, por lo que los programas de reintroducción suelen fracasar. Jamieson recuenta los limitados éxitos de la reinserción del cóndor de California y el lobo. Des- 
de 1982, fecha en que inició el programa de reinserción, la población de cóndores aumentó de 22 a 219 ejemplares, pero la mayoría de las aves reinsertadas no sobrevivieron. Peor aún, Jamieson reporta que en este período sólo seis huevos han sido producidos en estado salvaje y que sólo un polluelo alcanzó a desarrollarse'. El problema con los lobos reintroducidos es que no suelen evitar a los humanos, provocando fuertes choques entre ambas especies con resultados fatales para los lobos. Lo mismo ha sucedido con felinos, grandes simios, osos, rinocerontes o hipopótamos que han sido reintroducidos a sus hábitats (Jamieson, 2006: 139). Con todo, me parece que el problema más importante para los programas de reinserción es que los ecosistemas naturales en conjunto están desapareciendo y perdiendo su viabilidad para sostener a las distintas comunidades vegetales y animales que los constituyen. La consecuencia para los animales en cautiverio es que resultan -o resultarán- ser los últimos ejemplares de una especie que no tiene ningún otro medio para prosperar. Serán animales absolutamente ajenos a la naturaleza y estarán confinados permanentemente a una moderna arca de Noé, la cual no tendrá jamás un puerto para desembarcarlos².

1 En la sección «Los zoológicos en México» cito una nota informativa sobre el programa del Zoológico de Chapultepec de reinserción de esta especie en la Sierra de San Pedro Mártir, en Baja California. No tengo información sobre la relación de tal programa con el mencionado por Jamieson; en todo caso, la información en México no destaca dificultades importantes en su programa de reinserción.

2 Valerious Geist presenta una versión menos pesimista del final del arca. Según esta versión, el arca nos permitirá conservar a las especies mientras arreglamos los problemas ambientales del ecosistema terrestre (Geist, 1996). En la medida en que los propios humanos somos responsables del severo deterioro ambiental que padece el planeta, tal vez no sea mala idea mantener esta posición menos pesimista. Al menos, nos invita a hacernos responsables del daño ambiental y de su arreglo. 


\section{Educación y sacrificio de animales excedentes}

Los zoológicos operan con recursos económicos muy escasos, lo que los obliga a sacrificar a los animales excedentes. Con animales excedentes se refieren a aquéllos que ya no son necesarios para el programa del zoológico. El concepto refleja el punto de vista de los humanos y sus necesidades y es una noción utilitarista (Lacy, 1996: 188). En otras palabras, la noción de animales excedentes y la necesidad de sacrificarlos no refleja los intereses de los animales. Sin embargo, dadas las condiciones, los zoológicos no parecen tener alternativa: «No sacrificar mata animales. Si los excedentes no son sacrificados, los animales no pueden ser alimentados porque los recursos necesarios para sostenerlos son consumidos por el animal excedente» (Lacy, 1996: 190).

Estas condiciones resaltan muchos de los problemas éticos que enfrentan los zoológicos hoy en día. Casi parece que los zoológicos están en medio de una paradoja: la escasez de recursos los obliga a sacrificar animales excedentes, pero en orden de mitigar tal escasez tienen que promoverse como fuentes de entretenimiento y atraer personas. Una buena forma de hacerlo es convertir a algunos animales en atracciones. Ciertas especies resultan atractivas para los seres humanos y los zoológicos suelen explotarlas. Por ejemplo, recuérdese cómo usan a los pandas, los elefantes, los simios de ojos grandes, etc. Además, las crías son un foco importante y para aprovecharlo, los zoológicos promueven campañas para bautizarlas y para exhibir cómo son alimentadas, juegan o exploran su limitado mundo. El ejemplo que viene pronto a la mente es la cría de oso polar del zoológico de Berlín, Knut, y su triste final (murió sorpresivamente en mar- 
zo del 2011)3. Knut es un buen ejemplo de esta paradoja, ya que, al ser rechazado por su madre, inmediatamente se convirtió en un animal excedente; no era viable para sobrevivir en cautiverio candidato para ser sacrificado. En lugar de esto, el zoológico de Berlín lo convirtió en una atracción mundial (por ejemplo, cada aspecto de su vida se transmitió a través del canal en internet del zoológico) y el zoológico obtuvo así importantes ganancias ${ }^{4}$. Este caso es un buen ejemplo de cómo los zoológicos tienden a disneyficarse, esto es, a convertirse en sucursales del higiénico y dudoso Disneyland (un mundo bien caracterizado porque suele antropomorfizarse a las figuras centrales y por carecer de alusiones explícitas al sexo y a la muerte (cf. Parker, 2017). La mayoría de los zoológicos, efectivamente, están más interesados en el negocio del entretenimiento que en la preservación de especies (Jamieson, 1996: 53). Ahora la paradoja ética en cuestión es más fácil de apreciar: debido a los escasos recursos, los zoológicos tienen que sacrificar animales excedentes, pero muchas veces para mitigar dicha escasez convierten a ciertos animales en atracciones y, como en el caso de Knut, no son sacrificados.

¿Justifican las ganancias obtenidas de esta manera a prácticas como éstas? Me parece dudoso que puedan justifi-

3 Ver la nota periodística «Knut the Business-Bear». Recuperado el 17 de febrero de 2017, de http:/ / www.spiegel.de/international/zeitgeist/ polar-bear-turned-cash-cow-knutthe-business-bear-a-482368.html

4 Hay muchos recursos en línea para documentar este caso y cómo el zoológico de Berlín rompió su propio récord de asistentes y ganancias, ya sea directamente por el pago de entradas o por la venta de parafernalia. Especialmente relevantes me parecen: Moore, 2007; cgh, 2007; Burke, 2007. Sobre las causas de su muerte, una forma de encefalitis no infecciosa presente también en seres humanos, puede consultarse: Ghose, 2015 y H. Prüss, 2015. A partir de este caso se estableció que esta forma de encefalitis puede ser «relativamente común en el reino animal», de modo que, al menos en principio, podría ser tratada. Es raro un ejemplo, me parece, de cómo la investigación patológica realizada con animales en cautiverio podría tener un resultado positivo. 
carse porque los zoológicos subordinan la conservación y el cuidado de los animales al espectáculo y el entretenimiento. Incluso tomando en cuenta estas ganancias, los zoológicos no satisfacen, como hemos visto, sus tareas de investigación, conservación y educación. Estas prácticas de explotación de los animales muestran que el interés principal de los zoológicos es el entretenimiento, la menos interesante de sus tareas. Ésta es una consecuencia esperada del punto de vista utilitarista que priva en los zoológicos. En efecto, como sostiene Lacy, «los zoológicos usualmente evitan sacrificar animales excedentes para reducir la molestia humana. Las decisiones están basadas en los derechos de los humanos para tener vidas felices, no en consideraciones de los derechos de los no-humanos» (1996: 191). El público no hubiera aprobado el sacrificio de Knut. La actitud del público hacia los animales en los zoológicos es considerarlos mascotas. Llama la atención que entre el público no suele existir el mismo interés por otros animales en cautiverio, como los animales en granjas o en laboratorios (Wickins-Drazilova, 2006: 28).

Me parece que esto también indica que los zoológicos no cumplen a cabalidad con su tarea de educar al público. Bautizar a los animales, destacar aquellos aspectos de su conducta y condición que atrae la atención del público y crear campañas promocionales con representaciones antropomorfizadas, sólo contribuye a distorsionar la percepción pública de los animales. Éstos dejan de ser criaturas peculiares, fascinantes, incluso mortales, y se convierten en mascotas, en tiernas crías, «changuitos chistosos» o «elegantes felinos». El interés de los zoológicos por entretener domina sobre sus otras tareas e incluso parece medrar a costa de ellas.

Hay otros aspectos de la práctica de sacrificar animales excedentes que invitan a la reflexión ética. Es un hecho que 
los zoológicos sacrifican animales excedentes, pero debido al punto de vista utilitarista mencionado y a las molestias que trae para el público suelen hacerlo de manera privada. Recientemente, en 2014, el zoológico de Copenhague se hizo mundialmente famoso por sacrificar de un disparo a Mario, una jirafa macho de unos dos años de edad, conducir una disección pública de su cadáver y conservar sus restos para alimentar a los leones del zoológico (Parker, 2017). El caso se hizo viral en los medios porque dos días antes de sacrificarlo se filtró un correo electrónico a la prensa acusando al zoológico de pretender matar a Mario y de efectuar la disección en público. Las autoridades del zoológico sospechan que el correo fue filtrado por algún visitante, quien se refirió a la jirafa como Mario. El zoológico no divulgó este nombre al público, si bien se lo asignaron para identificar a este espécimen con fines prácticos (sobre todo alimentarlo y darle medicamentos); comúnmente, con el fin de no antropomorfizar a los animales y contribuir a la educación del público, los zoológicos de Dinamarca no divulgan al público el nombre que les dan. De hecho, el proyecto de sacrificar a esta joven jirafa tenía el doble propósito de contribuir a la sustentación del zoológico, manteniendo una población viable de jirafas, y educar al público. El zoológico invitó, en efecto, al público, sobre todo a niños, a presenciar la disección. Durante ésta, alentaron a los niños a hacer preguntar y a participar en el proceso dirigiendo ocasionalmente a los veterinarios. Las autoridades del zoológico quedaron satisfechas de la enorme cantidad de preguntas que respondieron $y$, desde su punto de vista, todo el asunto fue una gran experiencia educativa.

Los detractores del zoológico de Copenhague parecen ser de dos tipos. Por un lado, activistas defensores de los animales y, por otro lado, varios zoológicos de Europa y del mundo 
preocupados por la mala fama que el sacrificio público de un animal les trae. La posición predominante de los zoológicos, ante el innegable hecho de que practican sacrificios de sus animales excedentes, parece ser la de jamás hablar de eso y, desde luego, ocultarlo al público. El propio zoológico de Copenhague sacrifica entre veinte y treinta animales por año (usualmente chivos, antílopes, renos y ocasionalmente leones, tigres, cebras y osos) (Parker, 2017). La decisión de hacer público el sacrificio y la disección de la jirafa Mario -y posteriormente de otros animales- se justificó por el propósito de contribuir a la educación del público. Desde mi punto de vista, ofrece una visión realista de las prácticas de sacrificio al interior de los zoológicos y permite encarar públicamente hechos que son de interés general, como la existencia misma de los zoológicos y los medios a los que recurren para realizar sus tareas esenciales.

El reclamo de los defensores de los animales permitió hablar de otros temas. Usualmente, los zoológicos intercambian animales excedentes, pero la jirafa sacrificada nació en un momento de «plenitud de jirafas» en Europa. El asunto es que aún en cautiverio las jirafas forman familias con pocos machos y muchas hembras. Cuando un joven macho alcanza la edad adulta, suele ser atacado por el macho dominante. No es raro que los jóvenes adultos sean severamente lastimados en estos encuentros. De modo que no había lugar para esta joven jirafa, ni en los zoológicos de Copenhague ni en otros de Europa. Esto mismo muestra que las jirafas viven en familias, son animales gregarios. Por esta razón el zoológico de Copenhague rehusó la oferta de un zoológico sueco privado para adoptar a Mario. Este zoológico no tenía ninguna jirafa y Mario estaría solo. Las autoridades del zoológico adujeron que sus contrapartes suecas «no tenían ni una pista 
de qué era una jirafa» (Parker, 2017), lo que sugiere que ellos sí saben qué es una jirafa. Volveré a este asunto más abajo. Algún otro zoológico, fuera de Europa, mostró algún interés en la jirafa que sería sacrificada, pero, como hemos visto, es tan grande la cantidad de animales excedentes sacrificados en todo el mundo, que no parece viable buscar un nuevo hogar para cada uno. Los responsables del zoológico danés se resistieron a caer en lo que meramente parecían campañas de relaciones públicas dirigidas a la simpatía del público por la joven jirafa, que eran promovidas por otros zoológicos. En efecto, ante la viral difusión del sacrificio de Mario algunos zoológicos del mundo mencionaron la posibilidad de adoptarlo (Parker menciona uno en Inglaterra y otro en China), pero las autoridades de Copenhague no siguieron este camino $y$, una vez agotadas las opciones usuales de intercambio de animales dentro de la red de zoológicos en Europa a la que pertenecen, decidieron continuar con el sacrificio de la joven jirafa macho.

Se adujó también que el zoológico pudo haber tomado medidas para evitar la concepción de Mario. Este tipo de medida es común entre los zoológicos estadounidenses, pero muchos en Europa, incluyendo el de Copenhague, siguen la práctica de «criar y sacrificar». La justificación de esta práctica es que la contracepción acarrea diferentes problemas médicos para las hembras y, eventualmente, los animales en cautiverio tienden a volverse infértiles. Por eso los zoológicos les permiten aparearse y criar. El sacrificio de los animales excedentes, como hemos visto, es una consecuencia inevitable de esto. Mario mismo fue sacrificado de un balazo en la cabeza, como dije antes, lo que horrorizó a muchos defensores de los animales (si bien la ejecución no fue pública). La justificación de las autoridades para sacrificar de este modo a Mario 
era su interés en aprovechar su carne para alimentar a otros animales. La carne de un animal sacrificado por medio de sustancias químicas no se aprovecha como alimento porque queda contaminada.

Desde el punto de vista del propio zoológico de Copenhague, todas las razones que justificaron el sacrificio de Mario -al que erróneamente refieren ocasionalmente como eutanasia, pensando sólo en que murió instantáneamente y presuntamente sin dolor, y no en que su muerte de ninguna manera favorecía sus intereses- se justifican, en primer lugar, porque al sacrificarlo garantizan que su población de jirafas en cautiverio esté preparada genética y demográficamente para sobrevivir muchas generaciones. De este modo, además, defienden que sirven a la tarea de conservar la especie, pero, como hemos visto, esto parece un mito, toda vez que los animales en cautiverio carecen de las capacidades para sobrevivir en libertad o para contribuir a que la especie remonte la curva de la extinción (Parker, 2017). En consecuencia, tener una población de jirafas en cautiverio que pueda sobrevivir varias generaciones sólo parece servir a los intereses del zoológico. Se trata, una vez más, del punto de vista utilitarista que sólo toma en cuenta los intereses humanos. En segundo lugar, justifican el modo en que fue usado el cuerpo del animal sacrificado por la oportunidad de enseñar algo a los niños y al público en general. No parece increíble pensar que una vívida lección de anatomía despierte un fuerte interés científico en los niños y en cualquier persona (una pregunta que hizo algún niño fue por qué era tan grande el corazón de la jirafa). Esto por sí mismo parece deseable y encomiable, excepto porque no es la única forma de fomentar estas actitudes y, tal vez, tampoco sea la mejor, toda vez que contamos con muchos otros recursos educativos. Sin embar- 
go, convierte a la jirafa en un instrumento de los intereses humanos. Confirma, quizá de manera muy elocuente, que los animales en cautiverio, en zoológicos, acuarios, granjas, etc., están a nuestro servicio y que podemos disponer de ellos según nos parezca mejor. La propia organización del zoológico queda desenmascarada, así, como una institución vestigial, propia de una época en que la mentalidad humana creía que podía disponer sin medida de cualquier recurso natural y usarlo del modo que le pareciera mejor. Considero que en nuestros días tendríamos que pensar si hay lugar para instituciones que continúan con esta mentalidad.

Volvamos al asunto de que, en opinión de las autoridades del zoológico de Copenhague, el zoológico privado de Suecia no tenía ninguna pista de qué era una jirafa. Escribí que esto implicaría que los responsables de Mario sí sabían qué era una jirafa. ¿Realmente lo sabían? Lo que quiero poner en duda es si tenemos alguna pista de qué sucede con los animales en cautiverio en los zoológicos. ¿En qué los convertimos? En todo caso, en vista de las consideraciones anteriores, parece que un animal que ha sido declarado un excedente se convierte, en el mejor de los casos, en material didáctico para estimular la curiosidad y la actitud científica de los pequeños humanos y sus cuidadores. También en una pieza de entretenimiento y en fuente de proteína para aquellos animales que, desde el punto de vista humano, son viables para continuar en cautiverio, manteniendo por generaciones este ciclo de crianza, sacrificio, dudosa educación y entretenimiento. $\mathrm{O}$, en el peor de los casos, en un excedente vergonzoso que es sacrificado de manera secreta, de espaldas al público, y que confirma las inconsistencias de nuestras actitudes culturales hacia los animales. 


\section{De las rejas hacia fuera}

Podemos adoptar una perspectiva distinta sobre los zoológicos mirando de sus rejas hacia fuera. Rápidamente constataremos que operan en condiciones que, según han considerado algunos especialistas, anticipan una desaparición masiva de especies vegetales y animales, considerada ya la sexta extinción masiva de especies (Barnosky y otros, 2011; Ceballos y otros, 2015; Jamieson, 1996: 54; Conway, 1996: 2)5. Parece innegable que los ecosistemas terrestres y el mismo gran ecosistema que es el planeta, están fuertemente afectados por las economías humanas, esto es, por la economía humana. En estas condiciones, el compromiso con la conservación de especies de zoológicos, acuarios, parques nacionales y reservas, amerita revisarse. A este paso, en unas décadas los únicos ejemplares de muchas especies animales (por limitarnos ahora a ellos) serán aquéllos que estén representados en dichas instituciones. ¿Justifica esto la existencia de los zoológicos? ¿Podría la tarea de contribuir a la conservación de los animales darles un nuevo sentido?

Según el informe de 1992 del World Resources Institute, «la captura de animales para los zoológicos está regularmente enlistada entre las mayores amenazas para los animales salvajes» (citado por Conway, 1996: 3). De modo que, paradojicamente, los propios zoológicos son responsables de la crítica declinación de especies. Según vimos antes, difícilmente pue-

5 De acuerdo con Barnosky y otros (2011), una extinción masiva se define por la extinción de tres cuartas partes de las especies de la Tierra en un periodo de tiempo geológico muy corto. Hay evidencia de que nuestro planeta ha sufrido cinco extinciones masivas y, de acuerdo con los estudios citados, hay también evidencia de que ha empezado ya una sexta. Posiblemente hemos rebasado ya el punto de no retorno, i.e., no es posible revertir ya las condiciones de la sexta extinción masiva. 
den contribuir a reparar este daño toda vez que los animales en cautiverio no parecen viables para repoblar poblaciones salvajes de su propia especie. Lo más grave, con mucho, es que la magnitud del deterioro ambiental a nivel planetario está cerrando la posibilidad de contar con ecosistemas viables para reintegrar a los animales. (Como decía antes, los zoológicos son modernas arcas de Noé sin un puerto para dejar su preciosa carga). Tal vez la opción sea que los zoológicos colaboren estrechamente con las reservas naturales y los parques nacionales (Conway, 1996: 7).

En los últimos años hemos observado cambios en la actitud fundamental de varios zoológicos. Ahora parecen más preocupados por la conservación y la educación (aunque polémico, el caso del sacrificio de la jirafa Mario en el zoológico de Copenhague es un ejemplo de esto). También las reservas y parques naturales han cambiado y cada vez se parecen más a los propios zoológicos. El Parque Nacional Lago Nakuru fue completamente cercado en 1987. La World Conservation Union ha sugerido que los grandes mamíferos de África Oriental sean manejados como animales domésticos y parece que «es sólo cuestión de tiempo» para que suceda; una tendencia similar se aprecia en los parques y reservas en América (Jamieson, 1996: 53; Conway, 1996: 7). Si los ecosistemas naturales, como los hemos conocido hasta ahora, no serán viables en el futuro, entonces parece que nos acercamos a convertir al planeta entero en una gigantesca arca sin lugar de desembarco. Dadas las condiciones actuales del deterioro ambiental y el estado de nuestro conocimiento, no parece que tengamos alternativas interesantes. Ante esto, la experiencia acumulada en los zoológicos para conservar animales en cautiverio, que son percibidos ya por muchos como mascotas o, por lo menos, como animales domésti- 
cos, será muy valiosa. Los zoológicos han desarrollado el conocimiento y la técnica para lograr que las poblaciones animales significativas en cautiverio puedan reproducirse por varias generaciones. Además, las redes de zoológicos, que operan prácticamente de forma globalizada, garantizan un importante acervo genético.

Estas expectativas suscitan muchas preguntas. Los criterios de los zoológicos para formar sus colecciones de animales no suelen estar muy alejados de las preferencias no informadas del público. Los animales exóticos, los más llamativos, los que siempre han cautivado la atención humana, los que tienen potencial de ser atractivos, son los que destacan en sus colecciones. Animales menos interesantes, como insectos, artrópodos, aves comunes, etc., no suelen estar representados en sus colecciones $y$, desde un punto de vista holista, no podemos entender a un ecosistema sin la presencia de todos sus animales constitutivos (eso sin mencionar las especies vegetales, los organismos microscópicos y los complejos ciclos energéticos distintivos de cada ecosistema). Así, los zoológicos parecen reflejar más el punto de vista humano común, no educado, que uno informado sobre la naturaleza y sus poblaciones constitutivas. El caso de las reservas y parques naturales podría ser distinto, pero ¿qué tan distinto? En vista de la afectación que han sufrido por las economías humanas, tratar a los animales salvajes como animales domésticos implica intervenir en aquellos puntos críticos donde los ciclos energéticos de los ecosistemas se han roto. Por ejemplo, si una determinada variedad de alimentos deja de producirse naturalmente en un cierto ecosistema, los cuidadores humanos tendrán que buscar cómo reemplazarlo o proveerlo directamente a las especies que lo requieran. Si agentes patógenos externos afectan a las poblaciones, los 
cuidadores humanos tendrán que buscar remedios para los afectados. Es lo que hacemos con los animales domésticos: los alimentamos y cuidamos. Desde luego, también implica mantener el control sobre lo que sucede al interior de las rejas: qué, quiénes y cómo las pueden traspasar. Un mundo así será un mundo fragmentado y segmentado por rejas.

Una visión planetaria sobre los animales, como la que parece seguirse de los planteamientos anteriores, nos conduciría además a adoptar una posición holista sobre la naturaleza, es decir, la creencia de que toda la naturaleza es objeto de consideración moral. Desde este punto de vista, sin embargo, son las especies, sobre todo, las que reciben mayor atención. Los individuos no son tan importantes $y$, con base en tal postura, el objeto último de consideración moral es la naturaleza entera, con su ciclo completo de creación y consumo de energía, lo que, desde el punto de vista de los individuos, equivale a sostener que eventualmente todos seremos alimento -energía- para otros seres vivos. Si esta consecuencia es plausible, entonces también tendremos que prepararnos para ampliar la noción de sacrificio de individuos excedentes, como la jirafa Mario. «Animal excedente», en este contexto, no se definirá en función del programa de algún zoológico, sino posiblemente en términos más amplios, relativos a la viabilidad de un parque, una reserva o del planeta entero. En la medida en que no incluyamos en tales cálculos a los seres humanos, todo este marco de reflexión holista estará muy cercano al punto de vista utilitarista que parece regir las prácticas y políticas de los zoológicos, pero si los incluimos, entonces tendremos que responder a planteamientos relativos al valor intrínseco que tiene, incuestionablemente, cada vida humana.

La visión holista o planetaria de lo que es objeto de consideración moral tiene que responder a planteamientos como 
el llamado «enfoque de derechos» de los animales, propuesto y defendido por Tom Regan. De acuerdo con Regan, los animales son objeto de consideración moral porque poseen valor inherente que los habilita para ser sujetos de derechos y recibir un trato respetuoso, semejante al que brindamos a los seres humanos (2016). En consecuencia, así como respetamos fuertemente el derecho de cada persona humana a tener una vida, también deberíamos respetar el derecho de cada animal a tener una vida. Implica, desde luego, que no hay lugar para la noción de «animal excedente», como no la hay para la noción de «humano excedente».

Desde una perspectiva filosófica más amplia, me parece que estamos ante un capítulo más del debate entre utilitaristas y kantianos (en este contexto Regan representa a este último grupo, al sostener que los animales humanos y no humanos son portadores de un valor inherente). Por ahora, mi interés es sólo consignar el estado de la cuestión en que surge una vez más esta oposición entre posiciones éticas contrarias y sugerir que podríamos revisar nuestros marcos teóricos para abordar la ética del cuidado de los animales (Cavalieri, 2006). Muchas de las dificultades que tenemos para entender el grave deterioro ambiental que vivimos, yacen profundamente enraizadas en nuestra cultura y en los distintos marcos de pensamiento económico, psicológico y ético que la conforman. Dale Jamieson ha establecido, en esta línea, una tarea crítica para pensar en una ética que pueda responder por las determinaciones de la cultura. Discutiendo la responsabilidad de los zoológicos en el deterioro de los ecosistemas afirma que: «A lo que sí hay que culpar es a la peculiar esquizofrenia moral de una cultura que conduce a las especies al borde de la extinción y luego romantiza a las remanentes. Hasta que una especie está al borde de la extin- 
ción no parece apelar mucho a nuestra sensibilidad moral» (1996: 54). Esta idea nos conduce a pensar que el tema del cuidado de los animales en las condiciones actuales, no es meramente un asunto teórico, casi académico, sobre qué teoría ética nos sirve para enmarcar mejor nuestras preocupaciones y ofrecer respuestas; el asunto, sobre todo, tiene que ver con las determinaciones detrás de nuestra «sensibilidad moral». Por ejemplo, ¿por qué nos fascinan los animales de ojos grandes? ¿Por qué separamos tan fuertemente, en nuestras consideraciones morales, a los animales en granjas, circos, laboratorios, de los animales en zoológicos y aun en nuestros hogares? Conviene detenerse en este asunto y tratar de entender qué sucede con la psicología humana que nos lleva a tener criterios tan opuestos ante animales en condiciones similares. Esa esquizofrenia moral de nuestra psicología, de la que habla Jamieson, parece tener un lado utilitarista y otro kantiano. ¿Podríamos determinar cómo nos ha crecido esta peculiar sensibilidad moral hacia los animales y cómo, si es posible, desarrollar otras respuestas? Desde luego, necesitamos también discutir las tendencias de nuestra cultura que han desencadenado este grado de deterioro ambiental, como el consumismo excesivo, el despilfarro energético, la indiferencia ante la explotación del medio ambiente, por mencionar sólo algunas.

\section{Los zoológicos en México}

La mayoría de los zoológicos en México forman parte de la Asociación de Zoológicos, Criaderos y Acuarios de México, A.C. (AZCARM A.C.). Al menos en principio, los zoológicos agremiados comparten criterios éticos y legales en el trato que dan a sus animales cautivos. Destaca que uno de sus 
miembros, el zoológico de Chapultepec de la Ciudad de México ha participado con éxito en un programa de conservación para fortalecer a la población del cóndor de California del Parque Nacional San Pedro Mártir de Baja California. De 2014 a junio de 2016, la población alcanzó un número de 35 individuos «incluyendo a seis juveniles nacidos en vida silvestre». Este programa lo coordinan, además, la Comisión Nacional de Áreas Protegidas de México y el US Fish and Wildlife Service (AZCARM, 2016). En su sitio en línea no hay noticias similares de otros zoológicos en México. En general, la información sobre los programas y actividades de los zoológicos nacionales deja mucho que desear. Hasta donde puedo apreciar, en México no existen programas de investigación y educación sobre los animales en cautiverio en los zoológicos; a excepión del programa de conservación del cóndor de California, no parece haber ningún otro similar asociado a un zoológico en el país o, por lo menos, la información no está disponible. Por su parte, la Secretaría del Medio Ambiente y Recursos Naturales tiene el «Programa de recuperación y repoblación de especies en riesgo», pero no está con los zoológicos. Lo anterior alberga serias dudas sobre el cuidado que dan los zoológicos en México a sus poblaciones de animales en cautiverio. Parece que su única razón de ser es la de servir de alternativa de entretenimiento y ésta, como hemos visto, no es en absoluto una buena razón. Una consecuencia de privilegiar este enfoque es que los zoológicos en México no hablan de sus criterios para declarar a un animal como excedente, de sus sacrificios ni de lo que sucede con los cuerpos sacrificados. Esta opacidad no sirve a los intereses públicos y no permite que se adopten políticas públicas. 


\section{Bibliografía}

AZCARM. (28 de junio de 2016). «Se envían a vida silvestre primeras crías de cóndor de California», Zoológico de Chapultepec: http://www.azcarm.com.mx/noticias. html\#cuatro (Recuperado el 17 de febrero de 2017).

Barnosky, Anthony D., Nicholas Matzke, Susumu Tomiya, Guinevere O. U. Wogan, Brian Swartz, Tiago B. Quental, Charles Marshall, Jenny L. McGuire, Emily L. Lindsey, Kaitlin C. Maguire, Ben Mersey y Elizabeth A. FerrerN. M. (2011). «Has the Earth's sixth mass extinction already?» Nature, 471, 51-56. doi:10.1038/nature09678

Burke, J. (2007). Knut's a millionaire bear, while he's cuddly. Recuperado el 17 de febrero de 2017, de https: / / www. theguardian.com/environment/2007/ may/13/conservation.theobserver

Cavalieri, P. (2006). «The Animal Debate. A Reexamination». En P. Singer (Ed.), In Defense of Animals. The Second Wave (pp. 54-68). Oxford: Blackwell Publishing Ltd.

Ceballos, G., Paul, R. E., Anthony, D., Barnosky, A. G., Robert, M. P. y Todd M. P. (2015). «Accelerated Modern Human-induced Species Losses: Entering the Sixth Mass Extinction». Science Advances, 1(5), 1-5.

Conway, W. (1996). «Zoo Conservation and Ethical Paradoxes». En Norton, B. G., Hutchins, M., Stevens, E. F. \& Maple, T. R. (Eds.). Washington: Smithsonian Institution Press.

Geist, V. (1996). «Noah's Ark II: Rescuing Species and Ecosystems». En Norton, B. G., Hutchins, M., Stevens, E. F. \& Maple, T. R. (Eds.), Ethics on the Ark (pp. 93-101). Washington: Smithsonian Institution Press. 
Ghose, T. (2015). «Why Knut the Polar Bear Died So Suddenly». Recuperado el 17 de febrero de 2017, de http: / / www.livescience.com/52000-knut-polar-beardeath-identified.html

H. Prüss, J. L. (2015). «Anti-NMDA Receptor Encephalitis in the Polar Bear (Ursus maritimus) Knut». Scientific Reports (5). Obtenido de http://www.nature.com/articles/srep12805

Hutchins, M., Dresser, B. \& Wemmer, C. (1996). «Ethical Consideration in Zoo and Aquarium Research». En Norton, B. G., Hutchins, M., Stevens, E. F. \& Maple, T. R. (Eds.), Ethics on the Ark. Zoos, Animal Welfare, and Wildlife Conservation (pp. 253-272). Washington: Smithsonian Institution Press.

Jamieson, D. (2006). «Against Zoos». En P. Singer (Ed.), In Defense of Animals. The Second Wave (pp. 132-143). Oxford: Blackwell Publishing.

. (1996). «Zoos Revisited». En Norton, B. G., Hutchins, M., Stevens, E. F. \& Maple, T. R. (Eds.), Ethics on the Ark: Ethics, Animal Welfare, and Wildlife Conservation (pp. 52-66). Washington: Smithsonian Institution Press.

Lacy, R. (1996). «Culling Animals for Population Management». En Norton, B. G., Hutchins, M., Stevens, E. F. \& Maple, T. R. (Eds.), Ethics on the Ark: Ethics, Animal Welfare, and Wildlife Conservation (pp. 187-194). Washington: Smithsonian Institution Press.

Moore, T. (2007). «Baby bear becomes media star». Recuperado el 17 de febrero de 2017, de http:/ / news.bbc. co.uk/2/hi/europe/6486993.stm

Norton, B. G., Hutchins, M., Stevens, E. F. \& Maple, T. R. (Eds.). (1996). Ethics on the Ark: Ethics, Animal Welfare, 
and Wildlife Conservation. Washington: Smithsonian Institution Press.

Parker, I. (2017). «Killing Animals at the Zoo». The New Yorker. Recuperado el 16 de enero de 2017, de http: / / www. newyorker.com / magazine / 2017 / 01 / 16/ killing-animals-at-the-zoo

Regan, T. (2016). En defensa de los derechos de los animales (Primera edición electrónica ed.). (A. Tamarit, Trad.) México: FCE/UNAM/IIF.

Reagan, T. (1996). «Are Zoos Morally Defensible?» En Norton, B. G., Hutchins, M., Stevens, E. F. \& Maple, T. R. (Eds.), Ethics on the Ark: Ethics, Animal Welfare, and Wildlife Conservation. Washington: Smithsonian Institution Press.

Singer, P. (Ed.). (2006). In Defense of Animales. The Second Wave. Oxford: Blackwell Publishing.

Wickins-Drazilova, D. (2006). «Zoo Animal Welfare». Journal of Agricultural and Environmental Ethics, 19(1), 27-36. 


\section{Resumen}

Los zoológicos justifican su existencia en cuatro tareas fundamentales: la educación del público; la investigación hecha sobre la conducta y las condiciones que garantizan la salud de los animales en cautiverio; el cuidado de los animales, tanto los que están a su cargo como, desde una perspectiva más amplia, de los que están en peligro de extinción; y el entretenimiento del público. En este trabajo examino brevemente estas tareas y concluyo que sólo la de entretener al público es realizada con éxito $y$, muchas veces, a costa de las otras. Es necesario también reconocer que los zoológicos operan hoy en día en condiciones de grave deterioro ambiental, lo que hace pensar que podrían renovar su compromiso con el cuidado y conservación de los animales. Argumento que esta labor enfrenta fuertes dificultades porque desconocemos qué es un animal en cautiverio.

Palabras clave: animales, cuidado animal, conservación, cautiverio, ética.

\section{Abstract}

The zoos justify its existence in four fundamental tasks: the education of the public; the research done on the behavior and conditions that guarantee the health of animals in captivity; the care of the animals, both those in captivity in the zoos itself and, from a broader perspective, those in danger of extinction; and the entertainment of the public. In this paper, I briefly examine these tasks and conclude that only the task of entertaining the public is performed with some success and, often, at the expense of the other tasks. But it is also necessary to recognize that zoos today operate in conditions 
of serious environmental deterioration, which suggests that they could renew their commitment to the care and conservation of animals. I argue that this task too faces great difficulties and that we no longer know what is an animal in captivity.

Key words: animals, animal care, conservation, captivity, ethics. 